\title{
Are Anatomic Results Influenced by WEB Shape Modification? Analysis in a Prospective, Single-Center Series of 39 Patients with Aneurysms Treated with the WEB
}

\author{
(D)D. Herbreteau, (DR. Bibi, (D) A.P. Narata, (D). Janot, (DC. Papagiannaki, (D) S. Soize, and (D). Pierot
}

\begin{abstract}
BACKGROUND AND PURPOSE: Endovascular treatment with the flow-disrupter Woven EndoBridge aneurysm embolization system (WEB) is an innovative treatment for wide-neck bifurcation aneurysms. Prospective, multicenter studies have shown the high safety of this technique. Stability of aneurysm occlusion in long-term follow-up has been rarely studied. Moreover the "compression" phenomenon has been reported and seems to be associated with poor anatomic results. This prospective, single-center series analyzes the safety and efficacy of the WEB device in long-term follow-up in relation to WEB shape modification.
\end{abstract}

MATERIALS AND METHODS: All patients with aneurysms treated with the WEB were prospectively included in a data base. Demographics, aneurysm characteristics, adverse events, and anatomic results were retrospectively analyzed. Anatomic results and modification of the WEB shape on the follow-up examinations were independently evaluated by a core laboratory.

RESULTS: Thirty-nine patients were included. We observed few complications: intraoperative rupture in no patients (0.0\%) and thromboembolic events in 3 patients (7.7\%) with a permanent deficit in $1(2.6 \%)$. At short-term, midterm, and long-term follow-up, adequate occlusion was obtained in $86.8 \%, 83.3 \%$, and $87.5 \%$, respectively. Retreatment rates were low (5.1\%). At 6 months, WEB shape modification (compression/retraction) was observed in $31.6 \%$ of patients but was not associated with a lower rate of adequate occlusion.

CONCLUSIONS: This prospective, single-center series with WEB devices used in 39 patients during 3.5 years confirms data from previous multicenter studies. Treatment can be accomplished with good safety and efficacy, with a high rate of adequate occlusion. Anatomic results were not worse in case of WEB shape modification.

ABBREVIATIONS: AcomA = anterior communicating artery; DL = Dual-Layer; PcomA = posterior communicating artery; SL = Single-Layer; SLS = Single-Layer Sphere; WEB = Woven EndoBridge; WEBCAST = WEB Clinical Assessment of IntraSaccular Aneurysm Therapy

W ide-neck intracranial aneurysms occurring at vascular bifurcations are very challenging for endovascular therapies. ${ }^{1}$ Due to the width of the neck, deposition of coils into the aneurysm without protruding into the parent vessel is difficult, even with the help of the remodeling technique. ${ }^{2}$ Stent placement is a potential option for this kind of aneurysm; however, Y-stent placement is often necessary and the need for dual antiplatelet treatment limits its use to unruptured aneurysms. ${ }^{3}$ A similar problem is encountered with flow diverters, which can only be

Received April 21, 2016; accepted after revision July 7.

From the Department of Neuroradiology (D.H., R.B., A.P.N., K.J.), Bretonneau Hospital, University of Tours, Tours, France; University François-Rabelais (D.H.), Tours, France; Department of Neuroradiology (C.P.), Charles Nicole Hospital, University of Rouen, Rouen, France; and Department of Neuroradiology (S.S., L.P.), Centre Hospitalier Universitaire Reims, University Reims-Champagne-Ardenne, Reims, France.

Please address correspondence to Denis Herbreteau, MD, Neuroradiology Department, Hôpital Bretonneau, Université François Rabelais, 2 Boulevard Tonnelé, 37044 Tours, France; e-mail: denis.herbreteau@univ-tours.fr

$\equiv$ Indicates article with supplemental on-line table.

http://dx.doi.org/10.3174/ajnr.A4918 used for unruptured aneurysms. ${ }^{1,4}$ Moreover, the efficacy of flow diverters in the treatment of wide-neck bifurcation aneurysms has not been established, and there is a potential risk of occlusion or a decrease in the size of the bifurcation branches covered by the flow diverter. ${ }^{1,5,6}$ Flow disrupters are intrasaccular devices that disrupt the flow at the aneurysm neck, inducing intra-aneurysmal thrombosis. The WEB device (Woven EndoBridge aneurysm embolization system; Sequent Medical, Aliso Viejo, California) is currently the flow disrupter available for clinical use that has been most widely evaluated in multiple multicenter studies showing its safety and efficacy for the treatment of these complex aneurysms. ${ }^{7-13}$

However mid- and long-term anatomic results remain uncertain. In a recent small series, Cognard and Januel ${ }^{14}$ reported the so-called "compression phenomenon" associated with relatively poor anatomic outcome in mid- and long-term results. Even if this series is small and self-evaluated and the change of the WEB shape is probably related to retraction rather than compression, the potential clinical importance of this phenomenon should not 
be neglected and should be further analyzed. ${ }^{15}$ A retrospective European series also analyzing mid- and long-term anatomic results showed stable adequate occlusion in $81.1 \%$ and $89.7 \%$, respectively, but potential modification of the device was not analyzed. ${ }^{16,17}$

To further evaluate this important question, we analyzed midand long-term anatomic follow-up in a prospective single-center series.

\section{MATERIALS AND METHODS \\ Study Population}

Institutional review board approval was obtained, and informed consent was waived according to the design of the study.

From July 2012 (when the first patient was treated with the WEB in the department) to December 2015, patients treated at our institution (University Hospital, Tours) with the WEB were prospectively included in a data base. The decision for treatment and its technique (surgery or endovascular treatment) was decided on a case-by-case basis by a multidisciplinary team that included neurosurgeons and interventional neuroradiologists.

The decision for treatment with the WEB was made by the interventional neuroradiologists on the basis of aneurysm characteristics (location, size, and neck size).

\section{WEB Devices}

The WEB is a self-expanding, retrievable, electrothermally detachable device with nitinol braids placed within the aneurysm sac; it induces a flow disruption at the level of the neck and subsequently an intra-aneurysmal thrombosis. Several WEB devices were available at the time of this study. The WEB-Dual Layer (DL), initially used, has a second nitinol braid that is proximally placed inside the first nitinol braid.

From November 2013, the WEB-DL was no longer used and was replaced by WEB-Single-Layer (SL) and WEB-Single-Layer Sphere (SLS), which represent an evolution of the MicroBraid technology (Sequent Medical). The WEB-SL has a barrel shape, and the WEB-SLS is spheric. The WEB-SL and SLS are available in an expanded range of diameters between 4 and $11 \mathrm{~mm}$ and in heights between 3 and $9 \mathrm{~mm}$.

The most recent evolution of the device is the enhanced-visualization (WEB-EV), which incorporates composite wire made from nitinol and platinum.

Parallel to this evolution, the microcatheters used to deliver these devices had changed. Initially, the WEB-DL used Rebar 27 (Covidien, Irvine, California), Headway 27 (MicroVention, Tustin, California), and DAC 038 (Stryker, Kalamazoo, Michigan) according to the size of the device. Sequent Medical developed specific microcatheters for WEB treatment, including VIA 27 and VIA 33. Recently, the VIA 21 was introduced for WEB sizes between 4 and $7 \mathrm{~mm}$.

\section{Procedural Modalities}

Treatment with the WEB was performed in a manner similar to aneurysm coil treatment, with general anesthesia, intraoperative intravenous heparin, and a single femoral approach.

Several pre-, intra-, and postoperative antiplatelet therapy protocols were used according to aneurysm rupture status and alternative treatment options. For ruptured aneurysms, no antiplatelet treatment was administered during or after the procedure. In unruptured aneurysms, aspirin was given during the procedure and for 3 months after. When stent placement was used during the procedure, additional treatment with clopidogrel or ticagrelor was prescribed for 3 months, and aspirin, for at least 12 months.

Triaxial access was usually used with a long introducer sheath placed in the internal carotid artery or vertebral artery. A distal access catheter was placed in the intracranial portion of the ICA or vertebral artery, and a microcatheter was placed in the aneurysm.

Careful measurements of the aneurysm (transverse diameter and height) were performed in 2 orthogonal projections on $3 \mathrm{D}$ DSA. The mean transverse diameter and height were calculated to determine the appropriate sizing of the device. During the initial period, the size of the WEB device was chosen to fit the aneurysm sac. With increasing experience, we oversized the device in the transverse diameter by approximately $1 \mathrm{~mm}$ and undersized it in height by approximately $1 \mathrm{~mm}$ (the rule of $+1 \mathrm{~mm} /-1 \mathrm{~mm}$ ).

The WEB device was then carefully deployed in the aneurysmal sac. After deployment, a control angiogram was performed to check the position of the device and evaluate flow stagnation inside the aneurysm. If needed, the device was resheathed and repositioned. In case of inappropriate sizing, the device was removed and another device was deployed.

\section{Data Collection}

For each patient, we collected the following data: patient age, sex, and aneurysm status and aneurysm characteristics, including location, transverse diameter, height and neck size, type of device used (DL/SL/SLS), perioperative antiplatelet treatment, occurrence of complications during or after procedure, and the use of additional devices during procedure.

The preoperative World Federation of Neurosurgical Societies score was obtained in cases of ruptured aneurysms. ${ }^{18}$ The modified Rankin Scale score was obtained before treatment in patients with unruptured aneurysms and at 1 month.

Follow-up images were obtained and included MR imaging at 3 months, DSA at 6 months, MR imaging at 1 year, DSA at 2 years, and MR imaging every year afterward.

\section{Data Analysis}

All adverse events occurring during the procedure, hospital stay, and until the last follow-up were reported and analyzed, including thromboembolic events and intraoperative rupture. Morbidity was defined as $m R S$ of $>1$ when the preoperative $m R S$ was $\leq 1$ (or in case of ruptured aneurysm) and as an increase of 1 point when the preoperative $\mathrm{mRS}$ was $>1$.

A core laboratory evaluated anatomic results independently. Aneurysm occlusion was evaluated by using the 3-grade scale (complete occlusion, neck remnant, aneurysm remnant) immediately at the end of the procedure and during follow-up. Adequate occlusion was defined as complete occlusion or neck remnant. The core laboratory also evaluated potential modification of the WEB device, which was classified into 2 groups: no noticeable modification of the WEB shape and modification of the WEB shape. Modifications were evaluated by comparing, in similar angiographic views, the dis- 

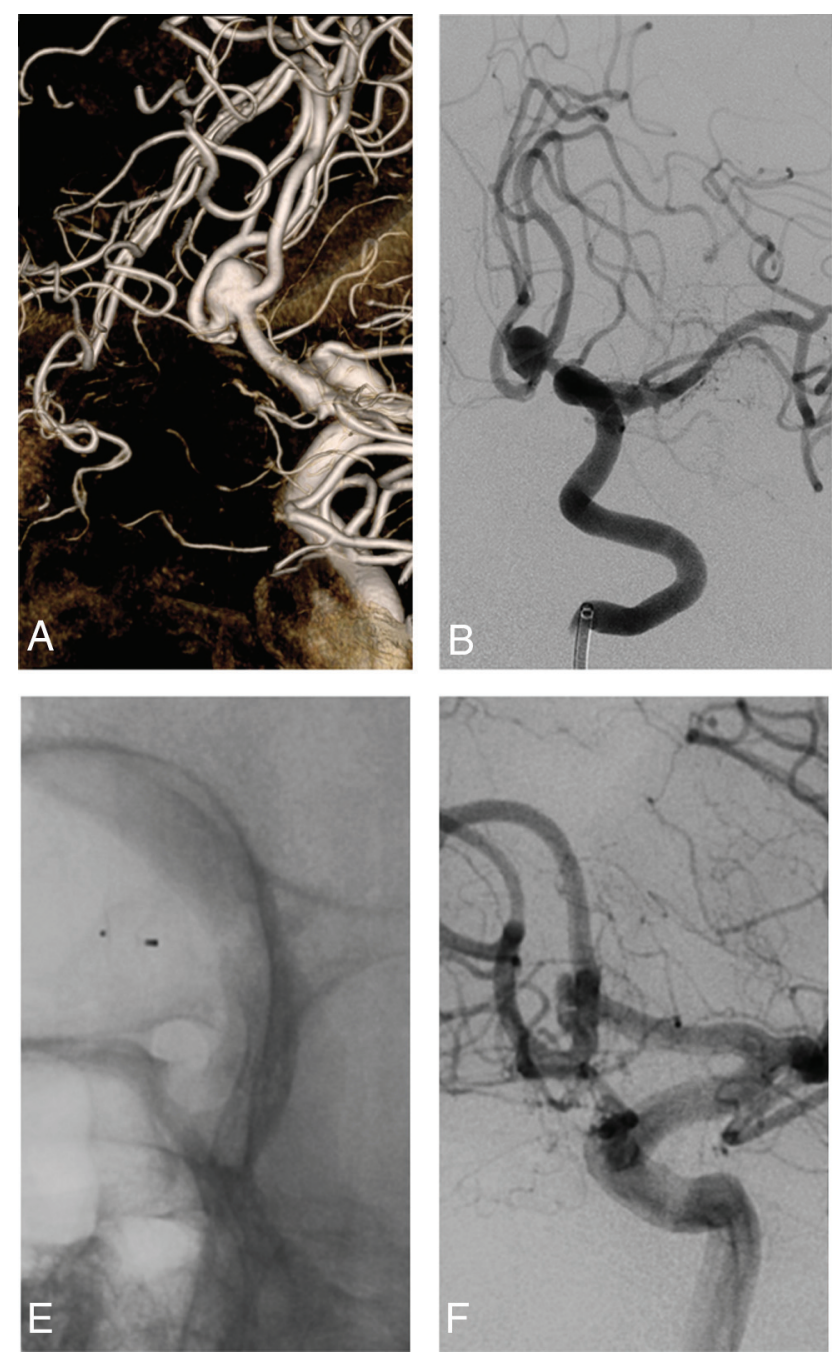
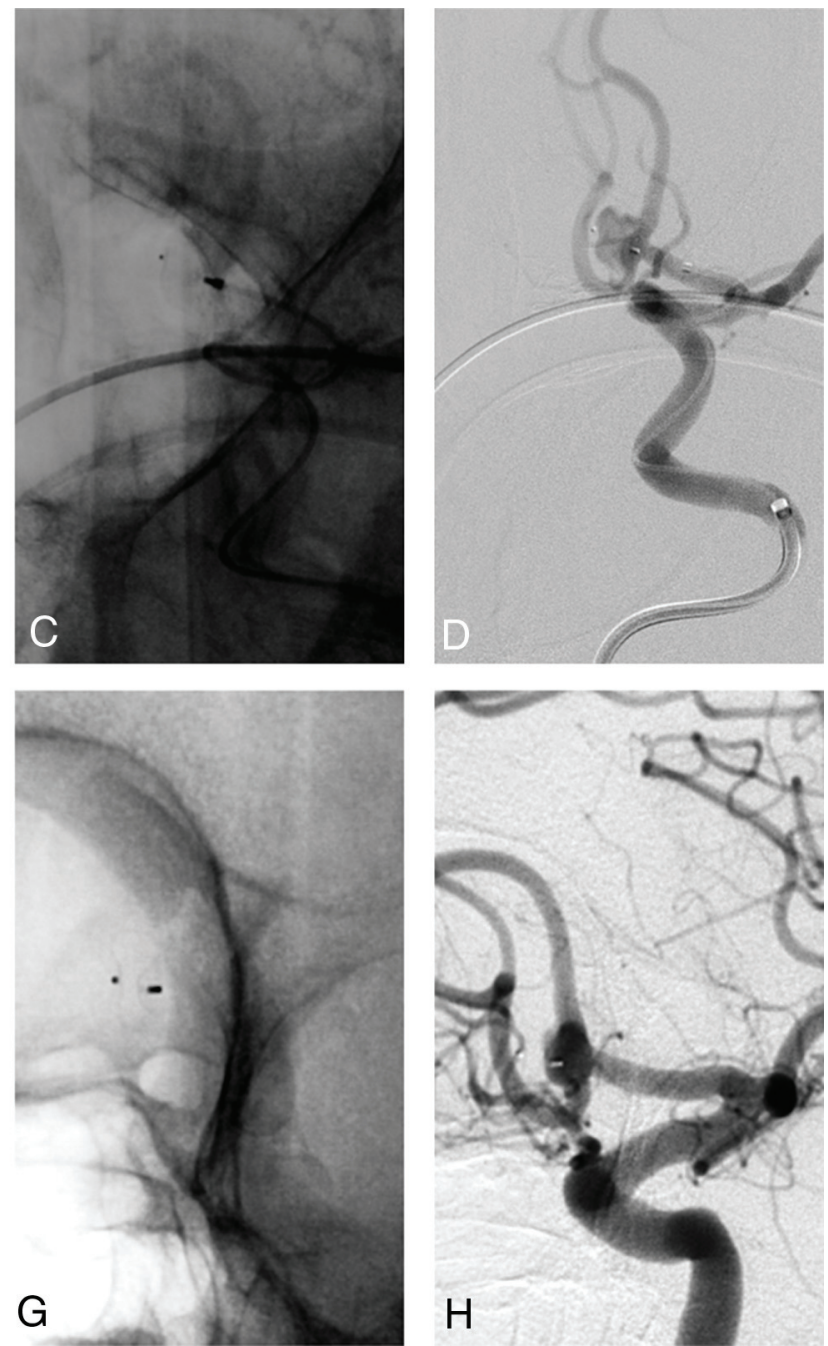

FIG 1. An unruptured AcomA aneurysm in a 78-year-old women (patient 21). Preoperative views: 3D-DSA (A) and oblique view (B). Operative views: WEB in place in the aneurysm, not detached $(C)$, and subtracted view $(D)$, showing contrast in the aneurysm. Six-month DSA: no change of the WEB shape $(E)$ and neck remnant $(F)$. Eighteen-month DSA: WEB shape modification $(G)$ and unchanged neck remnant $(H)$.

tance between the distal and proximal markers of the device and evaluating the concavity of the distal and proximal surfaces. No quantitative evaluation was performed.

Anatomic results and WEB shape modification were analyzed according to device sizing, which was classified into 2 groups according to the rule of $+1 \mathrm{~mm} /-1 \mathrm{~mm}$. The device was undersized when its transverse diameter was not at least $0.5 \mathrm{~mm}$ greater compared with the mean transverse diameter of the aneurysm, and it was appropriately sized when the device diameter was at least 0.5 $\mathrm{mm}$ greater than the mean transverse diameter of the aneurysm.

Anatomic results were also evaluated in relation to shape modification.

\section{Statistical Analysis}

Continuous variables were described as mean $\pm \mathrm{SD}$, with extreme values and categoric variables as a number and percentage. Categoric variables were compared by using the $\chi^{2}$ or Fisher exact tests, as appropriate. A $P$ value of .05 was considered significant. Analyses were conducted by using MedCalc statistical software for Windows (Version 11.4.3.0; MedCalc Software, Mariakerke, Belgium).

\section{RESULTS}

\section{Study Population}

Among $>650$ patients treated between July 2012 and December 2015 in our department, 39 patients $(6.0 \%)$ with 39 aneurysms were treated with the WEB device.

Of this population, 6 patients were included in the French Observatory study ${ }^{10} ; 5$ patients, in the WEB Clinical Assessment of IntraSaccular Aneurysm Therapy (WEBCAST) study; ${ }^{11}$ and 3 patients, in WEBCAST 2.

Mean patient age was $58.5 \pm 20$ years. Twenty-three $(59.0 \%)$ patients were women. Thirty-five $(89.7 \%)$ aneurysms were unruptured. No aneurysm was previously treated. Aneurysms were located at the MCA bifurcation in 21/39 (53.8\%), the anterior communicating artery (AcomA) in $9 / 39$ (23.1\%), the basilar tip in $5 / 39(12.8 \%)$, the ICA terminus in $2 / 39$ (5.1\%), the pericallosal artery in $1 / 39$ (2.6\%), and the posterior communicating artery (PcomA) in $1 / 39(2.6 \%)$. Aneurysm width (mean diameter) ranged from 4.3 to $9.5 \mathrm{~mm} ; 11 / 39$ $(28.2 \%)$ were $<5-\mathrm{mm}$ average width, and $28 / 39$ (71.8\%) were $\geq 5$ - $\mathrm{mm}$ average width. Neck size was $<4 \mathrm{~mm}$ in $7 / 39$ aneu- 

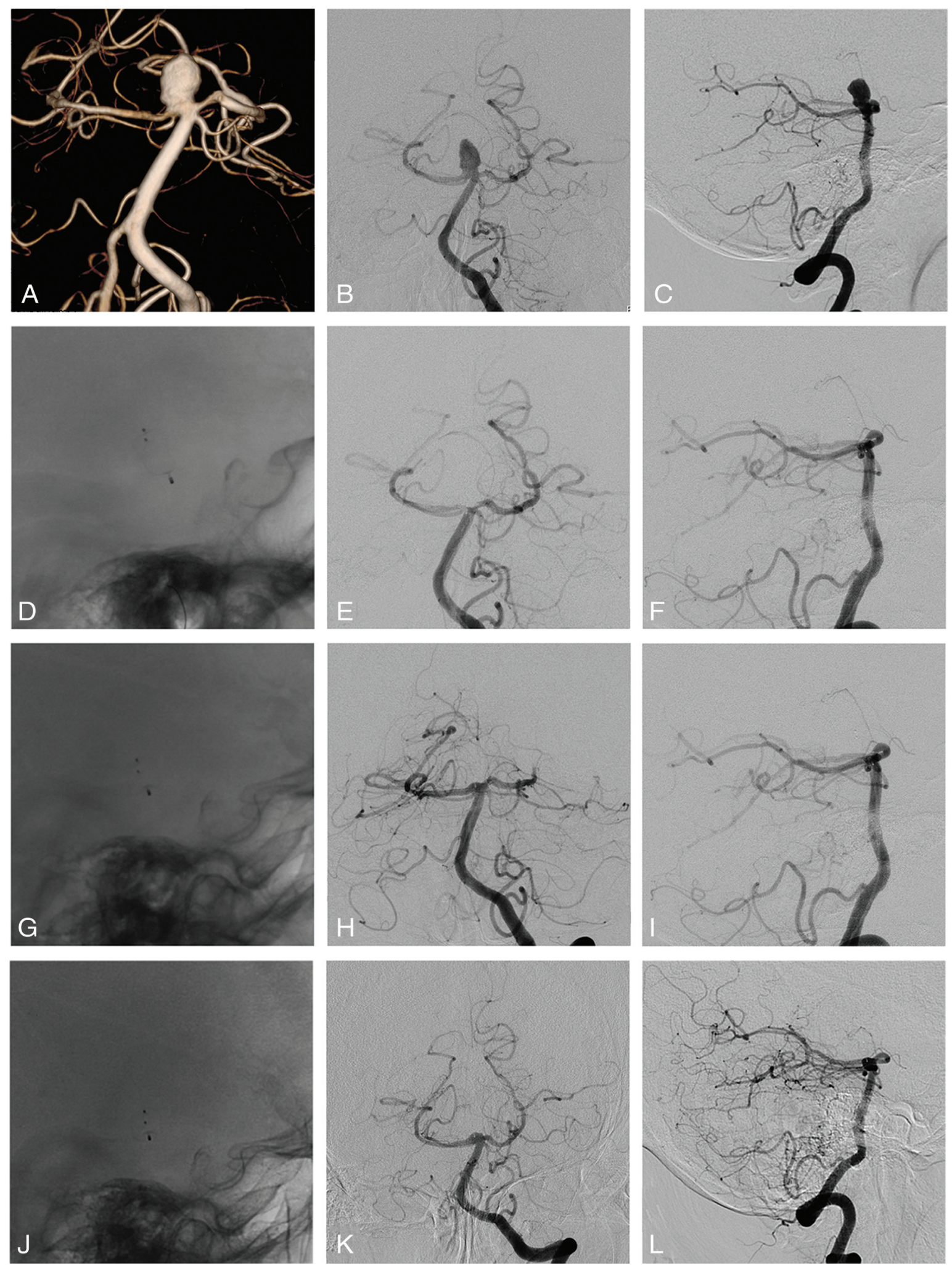

FIG 2. Unruptured basilar artery aneurysm in a 69-year-old women (patient 11). Preoperative views: 3D-DSA $(A)$ and frontal (B), and lateral views (C). Operative views: lateral, unsubstracted view showing the WEB $(D)$ and frontal $(E)$ and lateral $(F)$ views showing complete aneurysm occlusion. Six-month DSA: lateral, unsubstracted view showing the WEB change $(G)$ and frontal $(H)$ and lateral $(I)$ views showing complete aneurysm occlusion. Eighteen-month DSA: lateral, unsubstracted view showing the WEB change $(V)$ and frontal $(K)$ and lateral $(L)$ views showing complete aneurysm occlusion.

rysms $(17.9 \%)$ and $\geq 4 \mathrm{~mm}$ in $32 / 39(82.1 \%)$. All except 1 $(38 / 39,97.4 \%)$ met the definition of wide-neck bifurcation aneurysms by either a neck size of $\geq 4 \mathrm{~mm}$ or a dome/neck ratio of $<2$. Sixteen patients $(41.0 \%)$ were treated by using the WEB-DL; 18 (46.2\%), with the WEB-SL; and 5, (12.8\%) with the WEB-SLS. 


\section{Treatment Feasibility}

Technical success (deployment of the WEB in the target aneurysm) was achieved in 39/39 (100\%). Adjunctive stent placement was performed in 2 patients (5.1\%) due to WEB protrusion. In both cases, the WEB was sized according to the rule of $+1 \mathrm{~mm} /$ $-1 \mathrm{~mm}$.

\section{Adverse Events}

There was no intraoperative aneurysm rupture. Thromboembolic events occurred in $3 / 39$ (7.7\%) patients, with no clinical deficit in 2 and a permanent deficit related to stent placement in $1(2.6 \%)$. There were no delayed adverse events. Modified Rankin scale scores at 30 days were available for 39 patients: $\mathrm{mRS}$ was 0 in $37 / 39$ (94.8\%), 2 in 1/39 (2.6\%, this patient experienced an ischemic event after stent placement), and 4 in $1 / 39$ (2.6\%, this patient was already mRS 4 due to $\mathrm{SAH}$ ). Procedure- and device-related mortality was $0 \%$. Procedure-related morbidity (mRS 2 ) was $2.6 \%$.

\section{Aneurysm Occlusion and Retreatment}

Short-term follow-up (3-6 months) data were available for 38 patients ( 1 was lost to follow-up). Complete aneurysm occlusion was obtained in $23 / 38$ aneurysms (60.5\%), whereas neck and aneurysm remnants were observed in 10/38 (26.3\%) and 5/38 $(13.2 \%)$, respectively, leading to a rate of adequate occlusion of $86.8 \%$. At midterm follow-up (1 year), complete occlusion was obtained in 12/24 aneurysms (50.0\%); neck remnant, in 8/24 (33.3\%); and aneurysm remnant, in $4 / 24(16.7 \%)$, with adequate occlusion in $83.3 \%$. At long-term follow-up ( $\geq 18$ months), complete occlusion was obtained in 13/24 aneurysms (54.2\%); neck remnant, in 8/24 (33.3\%); and aneurysm remnant, in 3/24 aneurysms $(12.5 \%)$, with adequate occlusion in $87.5 \%$.

Two of 39 aneurysms (5.1\%) were retreated during the follow-up period. One (patient 22) had a $7.1 \mathrm{~mm}$, unruptured, AcomA aneurysm treated with an undersized WEB, retreated at 8 months with stent placement and coiling. The other (patient 8) had a 6.0-mm, unruptured, MCA aneurysm treated with an appropriately sized WEB. An aneurysm remnant was depicted at midterm follow-up without WEB shape modification and was retreated at 14 months.

\section{WEB Sizing, Shape Modification, and Aneurysm Occlusion}

According to the rule of $+1 \mathrm{~mm} /-1 \mathrm{~mm}$ (see above), the WEB device was undersized in $11 / 39$ patients $(28.2 \%)$ and appropriately sized in $28 / 39$ patients $(71.8 \%$ ). Among the 38 patients with short-term angiographic follow-up, 10 had an undersized WEB (26.3\%), and 28, an appropriately sized WEB (73.7\%).

WEB shape modification was observed in $12 / 38$ patients $(31.6 \%)$ with short-term follow-up. It was observed in similar percentages in patients with an undersized WEB $(3 / 10,30.0 \%)$ and an appropriately sized WEB $(9 / 28,32.1 \%)(P=.99)$. At longterm follow-up, the shape of the device was not modified in the 12 patients who already had a shape modification at short-term follow-up, and 1 additional patient had WEB shape modification.

In patents with an undersized WEB, short-term anatomic results were complete occlusion in $5 / 10$ aneurysms (50.0\%), neck remnant in $2 / 10(20.0 \%)$, and aneurysm remnant in $3 / 10$ (30.0\%). In patients with an appropriately sized WEB, complete occlusion was observed in 18/28 aneurysms (64.3\%); neck remnant, in $8 / 28(28.6 \%)$; and aneurysm remnant, in $2 / 28(7.1 \%)$. The rate of complete occlusion was not significantly different between both groups $(P=.67)$. Adequate occlusion (complete occlusion or neck remnant) was observed in 7/10 aneurysms with an undersized WEB (70.0\%) and in 26/28 aneurysms with an appropriately sized WEB $(92.9 \%)(P=.10)$.

At short-term follow-up, in the group of patients with WEB shape modification, anatomic results were complete occlusion in $3 / 12(25.0 \%)$, neck remnant in $7 / 12(58.3 \%)$, and aneurysm remnant in 2/12 (16.7\%). In the group of patients without WEB shape modification, anatomic results were complete occlusion in 20/26 (76.9\%), neck remnant in $3 / 26(11.5 \%)$, and aneurysm remnant in $3 / 26(11.5 \%)$. The rate of complete occlusion was significantly different between both groups $(P=.004)$. Adequate occlusion was observed in 10/12 aneurysms with WEB shape modification $(83.3 \%)$ and in 24/26 aneurysms without WEB shape modification $(92.3 \%)(P=.64)$. The percentage of neck remnants was significantly different between both groups $(P=.004)$.

\section{DISCUSSION}

This series reports the initial experience with the WEB device in aneurysm treatment. It explains the relatively low percentage of patients treated with this technique $(6.0 \%)$ because indications at the beginning were limited to selected cases with wide-neck bifurcation aneurysms difficult to treat with other techniques.

As demonstrated in previous Good Clinical Practice series, treatment with the WEB was highly feasible with no failures in this series. ${ }^{7-13}$ Most aneurysms were bifurcation aneurysms located at the MCA, basilar artery, ICA, and AcomA. More atypical locations were also treated, including the PcomA and pericallosal artery. Some aneurysm locations (AcomA, PcomA, pericallosal artery) proved more challenging to treat. In addition, aneurysms with excessive angulation versus the parent artery sometimes proved more difficult. Recent improvements to the WEB delivery system (0.021 profile and VIA 21) facilitate treatment of these aneurysms. The WEB is a safe and efficient alternative to balloonremodeling treatment, stent placement, flow diversion, or clipping. The single-balloon remodeling technique is less efficacious and more difficult in bifurcation aneurysms. ${ }^{2}$ Moreover, the double-balloon technique can be used, but it is technically more challenging. Stent-assisted coiling and flow diversion are typically reserved for patients with unruptured aneurysms because double antiplatelet treatment is required and is more limited in bifurcation aneurysms (especially with flow diversion). Moreover, the anatomic evolution (possible stenosis) of a small vessel such as the MCA filled with 2 intermingled stents remains unknown. The use of intraluminal flow diverters for the treatment of bifurcation aneurysms is also not simple because 1 or several bifurcation branches will be covered by the flow diverter with the potential risk of occlusion. ${ }^{5,6}$

In our series, all except 4 patients were treated for unruptured aneurysms, mostly due to the logistic organization (devices not available at all times on-site in our department), and antiplatelet therapy was conducted according to our routine protocol for unruptured aneurysms. Because no pre- or intraoperative antiplatelet treatment is needed for WEB treatment and because a rapid 
restriction of flow is observed at the level of the aneurysm dome, we recently used the WEB device for ruptured aneurysms. ${ }^{19,20}$ Larger series are needed to confirm the initial good results in this subgroup of patients.

Safety was good with no mortality and low treatment-related morbidity (1 patient, $2.6 \%$ ). There was no intraoperative rupture and a limited number of thromboembolic events (3/39 patients, $7.7 \%), 2$ without any clinical worsening. There was also an ischemic event in a complex case in which the placement of a stent was necessary due to WEB protrusion. A postoperative decrease of blood pressure led to this ischemic lesion with clinical worsening (mRS 2). Due to the small number of patients and events, it is not possible to compare safety in patients treated with the WEB-DL versus the WEB-SL/SLS. These results are in line with data from the Good Clinical Practice studies, despite this series including the first cases treated with this new technique (thus, the learning curve). ${ }^{10-13}$

The increasing use of coiling for aneurysm treatment has been associated with a depiction of recanalization as one of the limitations of the endovascular approach. Therefore, long-term stability of aneurysm treatment is a critical issue after endovascular treatment, especially for wide-neck aneurysms, which are prone to recurrence. From the literature, recanalization occurs for $8 \%-$ $33.6 \%$ of aneurysms treated with coils, with $7 \%-10 \%$ retreatment. ${ }^{21-23}$ These rates have led to the development of new tools, including the flow disrupter.

Data regarding the stability of WEB aneurysm treatment are still relatively limited. Animal studies conducted in the rabbit elastase aneurysm model showed that treatment with the WEB device was associated with high rates of immediate- and longterm aneurysm occlusion. ${ }^{24}$ In the recent analysis of the cumulated population of 2 Good Clinical Practice studies, adequate occlusion (complete occlusion and neck remnant) was obtained in $82 \%$ of aneurysms at 1 -year follow-up. ${ }^{13}$ In a retrospective European series, adequate occlusion was observed in $81.1 \%$ in short-term follow-up (median, 6 months) and $89.7 \%$ in midterm follow-up (median, 13 months). ${ }^{16}$ In the same series, long-term follow-up was analyzed in a subgroup of 26 aneurysms, showing adequate occlusion in $84.2 \%$, with stability of aneurysm occlusion between midterm and long-term in all cases. ${ }^{17}$ Similar results were obtained in the present series. Adequate occlusion was obtained in $86.8 \%(33 / 38)$ at short-term follow-up (6 months), $83.3 \%(20 / 24)$ at midterm follow-up (1 year), and $87.5 \%(21 / 24)$ at long-term follow-up ( $\geq 18$ months). The rate of adequate occlusion was similar at different follow-up intervals.

Two aneurysms were retreated with stent-assisted coiling (retreatment rate: $5.1 \%$ ) during the follow-up period: 1 between 6 months and 1 year and 1 between 12 and 18 months. The retreatment rate was similar to that reported in the cumulated populations of the WEBCAST and French Observatory studies (3.6\%).

A recent small series reported disappointing anatomic results potentially related to WEB compression. ${ }^{14}$ Adequate occlusion was observed in $71.5 \%$ of cases at short-term follow-up and $57.2 \%$ of cases at long-term follow-up. For the authors, these poor results were related to WEB compression. The potential phenomenon of so-called WEB compression is a decrease in the height of the device owing to the deepening of the proximal and distal con- cave device recesses during follow-up. Because both the proximal marker (near the aneurysm neck) and the distal marker (near the aneurysm apex) move toward the center of the device with time, one hypothesis is that the mechanism responsible for this phenomenon is likely associated with clot organization/retraction. ${ }^{15}$ The present series provides important insights into this phenomenon. The phenomenon is relatively frequent $(31.6 \%)$ and, at least in this series, is not related to WEB sizing. The phenomenon is observed in similar percentages in patients treated with undersized and appropriately sized WEBs $(30.0 \%$ and $32.1 \%$, respectively). On the other hand, adequate occlusion is more frequent but not significant when there is no WEB shape modification (92.3\% compared with $83.3 \%$ in case of WEB shape modification). Moreover, the rate of complete aneurysm occlusion is significantly lower in case of WEB shape modification (25.0\%) compared with cases with no modification (76.9\%) due to a higher rate of neck remnants ( $58.3 \%$ and $11.5 \%$, respectively). Adequate occlusion is also more often obtained when the device is appropriately sized (92.9\%) than when an undersized device is used (70.0\%), but this result is not statistically significant due to the small number of patients in the groups.

This study has several limitations. First, it is a single-center, retrospectively analyzed series. Because cases were prospectively collected, it gives a precise idea of the good safety of the device; all cases included were also those treated at the beginning of our clinical experience with the WEB (learning curve). Moreover, it gives the opportunity to precisely analyze the anatomic results with several follow-up angiograms for some patients. Second, it was not a randomized study, and direct comparison with other techniques is difficult. However, in the absence of a reference technique for the treatment of wide-neck bifurcation, a randomized trial is difficult to design and probably not ethical. Third, the series is relatively small (39 patients), but long-term follow-up was obtained in a large number of patients, which permits analyzing precisely the stability of aneurysm occlusion with the WEB. However, the small number of patients in this single-center series limits the interpretation of WEB sizing and WEB shape modification on anatomic results. Fourth, the WEB shape modification was studied semiquantitatively by comparing the shape of the device postoperatively and at follow-up directly. It is important to conduct a quantitative study in a large series of patients, but it is beyond the scope of this study.

\section{CONCLUSIONS}

This prospective, single-center series with WEB devices in 39 patients, during a 3.5-year period, confirms data from previous multicenter studies. Treatment can be accomplished with a high degree $(100 \%)$ of technical success and safety. Efficacy is also good, with adequate occlusion in $83.3 \%$ at midterm follow-up and $87.0 \%$ at long-term follow-up in these difficult-to-treat wideneck bifurcation aneurysms. In this series, WEB shape modification was observed in $31.6 \%$ at 6 months and is associated with a significantly lower percentage of complete aneurysm occlusion and a higher percentage of neck remnants, with a similar rate of adequate occlusion.

AJNR Am J Neuroradiol 37:2280-86 Dec 2016 www.ajnr.org 
Disclosures: Denis Herbreteau-UNRELATED: Consultancy: Sequent Medical; Travel/ Accommodations/Meeting Expenses Unrelated to Activities Listed: Stryker, Codman, ev3. Richard Bibi-UNRELATED: Travel/Accommodations/Meeting Expenses Unrelated to Activities Listed: Sequent Medical invitation to Congress. Ana Paula Narata-UNRELATED: Consultancy: Sequent Medical.* Laurent PierotRELATED: Consulting Fee or Honorarium: Sequent Medical; Payment for Writing or Reviewing the Manuscript: Sequent Medical; UNRELATED: Consultancy: Blockade Medical, Medtronic, MicroVention, Neuravi, Penumbra, Sequent Medical. *Money paid to the institution.

\section{REFERENCES}

1. Pierot L, Biondi A. Endovascular techniques for the management of wide-neck intracranial bifurcation aneurysms: a critical review of the literature. J Neuroradiol 2016;43:167-75 CrossRef Medline

2. Pierot L, Cognard C, Spelle L, et al. Safety and efficacy of balloon remodeling technique during endovascular treatment of intracranial aneurysms: critical review of the literature. AJNR Am J Neuroradiol 2012;33:12-15 CrossRef Medline

3. Pierot L, Wakhloo A. Endovascular treatment of intracranial aneurysms: current status. Stroke 2013;44:2046-54 CrossRef Medline

4. Pierot L. Flow diverter stents in the treatment of intracranial aneurysms: Where are we? J Neuroradiol 2011;38:40-46 CrossRef Medline

5. Gawlitza M, Januel AC, Tall P, et al. Flow diversion treatment of complex bifurcation aneurysms beyond the circle of Willis: a single center series with special emphasis on covered cortical branches and perforating arteries. J NeuroIntervent Surg 2016;8:481-87 CrossRef Medline

6. Caroff J, Neki H, Mihalea C, et al. Flow-diverter stents for the treatment of saccular middle cerebral artery bifurcation aneurysms. AJNR Am J Neuroradiol 2016;37:279-84 CrossRef Medline

7. Pierot L, Liebig T, Sychra V, et al. Intrasaccular flow-disruption treatment of intracranial aneurysms: preliminary results of a multicenter clinical study. AJNR Am J Neuroradiol 2012;33:1232-38 CrossRef Medline

8. Pierot L, Klisch J, Cognard C, et al. Endovascular WEB flow disruption in middle cerebral artery aneurysms: preliminary feasibility, clinical, and anatomical results in a multicenter study. Neurosurgery 2013;73: 27-34; discussion 34-35 CrossRef Medline

9. Papagiannaki C, Spelle L, Januel AC, et al. WEB intrasaccular flow disruptor-prospective, multicenter experience in 83 patients with 85 aneurysms. AJNR Am J Neuroradiol 2014;35:2006-11 CrossRef Medline

10. Pierot L, Moret J, Turjman F, et al. WEB treatment of intracranial aneurysms: indications, feasibility, complications, and 1-month safety results with the WEB-DL and WEB-SL/SLS in the French Observatory. AJNR Am J Neuroradiol 2015;36:922-27 CrossRef Medline

11. Pierot L, Costalat V, Moret J, et al. Safety and efficacy of aneurysm treatment with WEB: results of WEBCAST Study. J Neurosurg 2016; 124:1250-66 CrossRef Medline

12. Pierot L, Moret J, Turjman F, et al. WEB treatment of intracranial aneurysms: clinical and anatomic results in the French Observatory. AJNR Am J Neuroradiol 2016;37:655-59 CrossRef Medline

13. Pierot L, Spelle L, Molyneux A, et al. Clinical and anatomical follow-up in patients with aneurysms treated with the WEB device: 1-year follow-up report in the cumulated population of 2 prospective, multicenter series (WEBCAST and French Observatory). Neurosurgery 2016;78:133-41 CrossRef Medline

14. Cognard C, Januel AC. Remnants and recurrences after the use of the WEB intrasaccular device in large-neck bifurcation aneurysms. Neurosurgery 2015;76:522-30; discussion 530 CrossRef Medline

15. Pierot L. Letter: WEB aneurysm treatment-occlusion stability and “compression." Neurosurgery 2015;77:E666-67 CrossRef Medline

16. Lubicz B, Klisch J, Gauvrit JY, et al. WEB-DL endovascular treatment of wide-neck bifurcation aneurysms: short- and midterm results in a European study. AJNR Am J Neuroradiol 2014;35:432-38 CrossRef Medline

17. Pierot L, Klisch J, Liebig T, et al. WEB-DL endovascular treatment of wide-neck bifurcation aneurysms: long-term results in a European series. AJNR Am J Neuroradiol 2015;36:2314-19 CrossRef Medline

18. Teasdale GM, Drake CG, Hunt W, et al. A universal subarachnoid hemorrhage scale: report of a committee of the World Federation of Neurosurgical Societies. J Neurol Neurosurg Psychiatry 1988;51:1457 CrossRef Medline

19. Caroff J, Mihalea C, D’Argento F, et al. Woven Endobridge (WEB) device for endovascular treatment of ruptured intracranial wideneck aneurysms: a single-center experience. Neuroradiology 2014; 56:755-61 CrossRef Medline

20. Liebig T, Kabbasch C, Strasilla C, et al. Intrasaccular flow disruption in acutely ruptured aneurysms: a multicenter retrospective review of the use of the WEB. AJNR Am J Neuroradiol 2015;36:1721-27 CrossRef Medline

21. Gallas S, Januel AC, Pasco A, et al. Long-term follow-up of $\mathbf{1 0 3 6}$ cerebral aneurysms treated by bare coils: a multicentric cohort treated between 1998 and 2003. AJNR Am J Neuroradiol 2009;30: 1986-92 CrossRef Medline

22. Benaissa A, Barbe C, Pierot L. Analysis of Recanalization after Endovascular Treatment of intracranial Aneurysm (ARETA trial): presentation of a prospective multicenter trial. J Neuroradiol 2015; 42:80-85 CrossRef Medline

23. Ferns SP, Sprengers ME, van Rooij WJ, et al. Coiling of intracranial aneurysms: a systematic review on initial occlusion and reopening and retreatment rates. Stroke 2009;40:e523-29 CrossRef Medline

24. Ding YH, Dai D, Schroeder D, et al. Experimental testing of the dual-layer Woven EndoBridge device using an elastase-induced aneurysm model in rabbits. Interv Neuroradiol 2016;22:299-303 CrossRef Medline 